itself. In many cases, however, the way in which it is done is open to severe criticism. To illustrate this he shows photographs of Thames House, Millbank, floodlighted, first when special attention is paid to the roof and skyline and secondly when they are neglected. In the first case, the effect produced is beautiful but in the second case the floodlighting is very disappointing, the building appearing dwarfed and incomplete. The floodlighting in the first case was designed by Sir Frank Baines, the architect responsible for the building, and he supervised its execution. It is also pointed out what an important part the reflection factor of the lighted portion of the front of the building plays. In floodlighting the front of the Institution of Electrical Engineers, London, for example, the aggregate total load on the 26 floodlights used is 39 kilowatts. Owing to lack of time, the front had not been steam-cleaned prior to the installation and so the average reflecting factor was only 7 per cent. If it had been steamcleaned, the average reflecting factor would have been increased about five times and so the saving, if the same total illumination were produced, would be about four-fifths of the present current bill.

\section{Electric Cooking on the Thermal Storage System}

SINCE coal can be produced at a uniform rate and stored ready for use as required, the plant necessary for its production has only to be capable of supplying the average demand. The same is true of oil and gas but not of electricity. Therefore the size of the necessary generating plant for electricity is fixed by the maximum and not by the average demand. As a rule the maximum output is about three times the average output and so most generating stations could treble their output provided the load was evenly distributed over the day and night. As capital charges usually represent an appreciable fraction of the selling price of electricity, any new demand which tends to level the load can be supplied economically at a reduced tariff. In thermal storage systems for heating buildings or for supplying hot water, use is made of this principle by supplying heat to the storage water at times of light load at a much reduced rate. In the case of electric 'cookers' using thermal storage, the problem is more difficult as the temperature required for cooking is much higher and the cost limits the use of too much thermal insulation. In an article on storage cookers in the General Electric Co.'s Journal for November, O. W. Humphreys and Dr. E. C. Walton describe different types of these devices used in America and various Continental countries as well as the 'magnet storage cooker'. Compared with the standard type of electric cooker, the latter has the following advantages. The cost of installation is very low as it is merely the cost of an extra lighting point in the house circuit. The cost of maintenance is also very low compared with the ordinary cooker, and no meter is required. When the electric supply is sufficiently cheap these cookers might well be used. Some are already in use in the Midlands in the homes of working-class people.

\section{Research in Plant Industry in Australia}

THE fifth annual report of the Australian Council for Scientific and Industrial Research shows that results of great economic value, far exceeding the total expenditure of the Council, have been achieved. Problems relating to the control of disease form one of the chief lines of investigation undertaken by the division of plant industry, and such outstanding success has been obtained in the control of bunchy top disease in bananas that it has led to the reestablishment of the crop on large areas. The heavy annual loss hitherto sustained from the development of bitter pit in exported apples should now be reduced to negligible proportions, since its relation to immaturity at picking time has been established. An additional activity of this division is the introduction from abroad of new varieties of plants likely to be of value, particularly in the drier districts. Following the success with which weed pests, such as St. John's wort, have been suppressed, the entomological division is extending the method of biological control to other noxious plants, and an appropriate insect for destroying the Noogoora burr having been recently discovered, on the completion of laboratory trials this fly will be liberated in the infested districts. The recently formed Division of Forest Products has carried out particularly valuable work on the seasoning of hard woods for the manufacture of cases, and has further devised a rapid and cheap method for treating wood to be used for butter boxes so as to avoid the development of taint, but although attention has been given mainly to problems of immediate importance, fundamental research has not been neglected.

\section{Weeds of Grassland}

IN spite of the increased attention paid to grassland farming in recent years, there is still a vast area of permanent grass of poor quality, and since the reduction of weeds is intimately associated with the best means for securing its improvement, the issue by the Ministry of Agriculture of "Weeds of Grassland" (prepared by H. C. Long, and published by H.M. Stationery Office, price 58 . net), should prove of great value. At the outset, emphasis is laid on the necessity for using clean seed when sowing land down to grass, as injurious weeds are readily introduced, and instances of the special dangers in the case of the rye-grasses and clovers are cited. The principles in eradicating weeds from grassland are those which make for general improvement in the herbage, and in many cases attention to drainage, manuring, grazing, etc., rather than direct methods of destruction (though spraying is considered), will lead to the eradication of undesirable species. A large number of the worst weeds that occur on grassland are dealt with individually, classification being made according to the natural orders to which they belong. A. short botanical description, in which technical terms are so far as possible avoided, coupled with 92 illustrations (18 of which are coloured) from seeding to fruiting stages, renders identification a comparatively simple matter, and points of interest such as the association

No. 3296, VoL. 130] 
of a weed with certain soil conditions, its possession of poisonous or other special properties, as well as the best methods for its eradication, are given in each case.

\section{Salad Crops}

THe growing of salad crops has become a highly specialised business in several parts of England and there seems no reason why the acreage devoted to this branch of horticulture should not be profitably extended. As an aid to growers, whether on a large or small scale, the Ministry of Agriculture has issued an illustrated bulletin (No. 55, H.M. Stationery Office, 1s. 6d. net), from which it is evident that with good management it is possible to have supplies for the market throughout the whole year. Lettuce is quite the most important crop that is included under the term salad, and the best methods for its cultivation in the field, in heated and unheated glasshouses or in frames, are described in detail. Some account is given of the varying methods adopted in different districts and the varieties found to be most satisfactory in each locality, while cultural methods in use in other countries such as America and France are also included. Watercress is another important crop grown for salad purposes. Although little difficulty is experienced in its cultivation, it is essential that the water in which it is grown should be of the highest quality as the industry has suffered considerable harm from cress grown in contaminated streams. Attention to local conditions and markets, and the choice of a suitable variety to meet these requirements, are also needed if the cress-growing is to prove a thoroughly profitable undertaking.

\section{Forest Flora of Syria}

AN expedition under the leadership of Dr. Alexander Eig, head of the Section of Systematic Botany and Ecology at the Hebrew University, Jerusalem, has been examining the forest and other flora of Syria (Science Service, Washington, D.C.). During the tour, the members of the expedition were able to collect valuable material for the herbarium as well as to complete plans for the Syrian Section of the new Botanical Garden at Mount Scopus. The party travelled twice throughout the length and three times across the width of Syria, and were able to fix in a preliminary fashion the line of demarcation between the Mediterranean zone and that of the Urano-Turanic region, the precise boundary between which was previously unknown. An important part of the expedition's work was a study of the forest species of Syria, and the investigations undertaken enabled the principal types of forest species, particularly in the Amanus and Cossus hill regions, to be determined. A study thus begun came to the knowledge of the French Governor of Jebel Druze. The expedition received great assistance from the French Government officials in the mandated territory north of the Sykes-Picot line, and the French Governor has asked Dr. Alexander Eig to advise on the subject of afforesting certain parts of the Jebel Druze region. The determination of the principal Syrian forest types will be, it is said, of considerable importance to the Botanical Garden on Mount Scopus.

\section{Revision of Ordnance Plans}

THE methods adopted in the field revision of the large-scale Ordnance Survey Plans, with some account of earlier methods, are described and explained in detail in a pamphlet by Capt. J. C. T. Willis ("An Outline of the History and Revision of the 25-inch Ordnance Survey Plans". H.M. Stationery Office. 28. 6d.). The revision in the field is carried out by methods of prolongation and intersection but new detail must be 'hung' on to the original survey and not on to matter added at a previous revision. The use of specially selected points on the original survey has been abandoned and the equal reliability of all the original detail is accepted. The newest development adopted to counteract the liability of errors in redrawing the revised sheet entails the use of 'coated' paper at that stage. This paper permits all old detail to be expunged chemically, without affecting the surface of the paper beneath. Then it is found possible to avoid the redrawing of old detail, which involves a saving in accuracy as well as in time. A method of partial revision has had to be adopted in the centres of town and cities on the ground of economy. This neglects minor alterations in back premises while concentrating on the alignment and position of street fronts. The pamphlet contains a number of practical examples of revision, illustrated by charts, and discusses the kind of errors the surveyor may make.

Weather Maps showing Typical Distributions of Pressure

A PAMPHLET has been produced (Air Ministry : Meteorological Office. Examples of Weather Maps showing Typical Distributions of Pressure. (M.O. 237, second edition.) Pp. 8. (London: H.M. Stationery Office, 1932.) $3 d$. net.) to meet the needs of those schools where another publication prepared by the authority of the Meteorological Committee entitled "The Weather Map", which forms an introduction to modern meteorology, is used as a textbook for the teaching of elementary meteorology. The latter work appeared a little more than two years ago (see NATuRE, 126. 755, Nov. 15; 1930). Being a comparatively expensive production (price 3s. net, compared with $3 d$. net in the case of the pamphlet under notice), it was regarded as unsuitable for distribution to individual pupils and accordingly six of the most important illustrative synoptic weather charts have here been selected from it so that pupils would be able with the pamphlet in front of them to follow the explanations of a teacher using "The Weather Map" as a textbook. The six figures selected are those numbered 9, 18, 21, 22,23 and 24 in the textbook, and give typical examples of a depression, anticyclone, secondary depression, V-shaped depression, wedge and col. There is no explanatory matter beyond a paragraph describing the weather corresponding with the various letters that appear on the map (the Beaufort weather notation is used), the method of showing the speed and direction of the wind, the temperature, andby means of isobars for 4 millibar steps-the dis. tribution of pressure. The two publications, both

No. 3296, VoL. 130] 